\title{
LA RELACIÓN HOMBRE-NATURALEZA ENTRE LOS lacandones de Nahá, Ocosingo, Chiapas ${ }^{1}$
}

\author{
Marin Roblero Morales
}

Resumen: A principios del siglo $\chi \chi$ se dan los primeros encuentros entre lacandones y otros grupos étnicos. En décadas posteriores ocurrieron múltiples eventos importantes en la Selva Lacandona que transformaron el espacio ecológico y sociocultural de sus habitantes. En la comunidad lacandona de Nahá los más trascendentes fueron la llegada de migrantes, visitantes y misioneros cristianos en 1944, junto con la formación del ejido miles de hectáreas en la selva que el gobierno les asignó después de concentrarlos y reubicarlos en una zona mejor comunicada. La nueva cosmovisión occidental, que acompañó esos cambios, contrastó con la religiosidad ancestral e incidió en la transformación de la relación hombre-naturaleza, transformación que ha resultado negativa para el entorno biótico de la región. Sin embargo, hay elementos de su cosmovisión que se han preservado y otros que se han adoptado, resignificado y transformado, y pueden ser alternativas aplicables a sus actuales condiciones ecológicas y socioculturales.

Palabras clave: Deterioro ecológico, religiosidad, cultos cristianos, naturaleza, lacandones.

Enviado a dictamen: 18 de febero de 2008.

Aprobación: 04 de junio de 2008.

Marin Roblero Morales, licenciado en Antropología Social, correo electrónico: marin_8021@hotmail.com.
Abstract: At the beginning of the twentieth century, we find the first encounters between the lacandons and other ethnics group. During the following decades, many important events occurred in the Selva Lacandona which transformed the ecological and sociocultural background of its inhabitants. In the lacandon community of $\mathrm{Naha}$ the most significant occurrences were the arrival of immigrants, visitors and Christian missionaries in 1944. The new occidental believes contrasted with the ancestral religiosity, transforming the relationship of man-nature resulting negatively for the biotic environment of the region. However, there are some elements of its cosmovision which continue, others changed their meaning, while others adapted and transformed. Some of these cultural elements can be applicable alternatives to our actual ecological and sociocultural conditions.

Key words: Ecological deterioration, religiosidad lacandona, Christian cults, nature, transformation.

\section{Introducción}

ctualmente, el deterioro ambiental se incre-
menta ante el impulso de las políticas y el
modelo desarrollista de industrialización. La "modernización" del campo ha llevado a esta sociedad a una crisis caracterizada por una pérdida acelerada de la calidad de vida de la población afectada por la 
deforestación, la erosión y la contaminación de suelos y aguas, inundaciones, enfermedades, pobreza, dependencia alimentaria, hacinamiento, entre otros problemas. Ante esta situación, nuestra sociedad podría recuperar las prácticas de muchos pueblos no occidentales que a través de la historia han obtenido los elementos para su subsistencia sin deteriorar su ecosistema.

La comunidad lacandona de Nahá, del municipio de Ocosingo, Chiapas, todavía conserva muchos elementos culturales ancestrales que nos permiten conocer, al menos en parte, esa forma de relacionarse con la naturaleza. Sin embargo, de acuerdo con mis observaciones en esa comunidad, considero que la relación hombre-naturaleza propia de la cosmovisión de los mayas lacandones, también tiende a transformarse ante el avance de la modernización, que entre los lacandones se inicia aproximadamente en la década de los cuarenta y posteriormente en los setenta con la dotación del ejido, la explotación empresarial de la selva, su integración al mercado y la posterior expansión de los cultos cristianos. Estos hechos cambiaron drásticamente la manera de vivir de ellos y derivaron igualmente en nuevas formas de relación con otros actores de reciente aparición en la región. Estas mutaciones se retroalimentan de manera negativa porque el entorno biótico, parte de su universo, se ha ido transformando desde entonces.

A pesar del proceso de cambios acelerados y aunque se han incorporado muchos elementos de los cultos cristianos, la cosmovisión de los habitantes de Nahá no ha cambiado totalmente. Concepciones y símbolos se resignifican ajustándose a su religiosidad, a sus relaciones sociales y a sus diferentes actividades agrícolas y no agrícolas permitiendo, no sin transformaciones, una continuidad del universo simbólico maya lacandón, quefunciona, en alguna medida, como elemento protector de su ecosistema.

\section{Antecedentes históricos}

A partir de 1880 se dan los primeros encuentros entre los lacandones y nuevos colonos de la Selva Lacandona.
Tres décadas después (1907), Alfred M. Tozzer publica los primeros estudios antropológicos sobre los lacandones.

Durante el siglo XX, varios elementos determinantes definidos en diferentes etapas actuaron como transformadores del ecosistema y la cultura de los lacandones, entre ellos podemos mencionar: la explotación maderera iniciada en 1884 (Villa Rojas, 1985), la migración indígena en 1940 (Vargas, 1998), la presencia de Petróleos Mexicanos (Erosa, 1994), el mercado de la palma xate (Chamaedoiasp.) (Marion, 1992), el crecimiento de la ganadería y agricultura extensiva iniciada en la década de los sesenta (Duby, 1993), además de la presencia de organismos financieros internacionales y dependencias de gobierno.

Pero el elemento que marca un punto de partida significativo en la reestructuración de la cultura de los lacandones fue la dotación presidencial, en 1972, de extensas tierras ejidales (614,321 Has) (Dichtl, 1988) para 180 lacandones, la concentración y reubicación de sus tres pequeñas comunidades lacandonas: Nahá, ${ }^{2}$ Metzabok y Lacanhá, sitios mejor comunicados entre sí y con Palenque. Esa dotación sirvió como base jurídica para la explotación de la madera de la selva lacandona. En 1975, el gobierno indujo la firma (la mayoría de los lacandones no sabían leer ni escribir, no tenían concepción del dinero e ignoraban de qué se trataba) de un contrato entre la Comunidad Lacandona y la Compañía Forestal Lacandona S. A. (COLOFASA), mediante el cual se autorizó la explotación anual de 35,000 metros cúbicos de maderas preciosas y 5,000 metros cúbicos de maderas corrientes tropicales a cambio de fondos económicos para el desarrollo y beneficios por más de diez mil pesos para cada lacandón adulto por la venta de la madera ${ }^{3}$ (De Vos, 2002, Marion, 1991, Nations, 1978).

Estos acontecimientos que respondían por un lado a la política indigenista integracionista y por el otro a la dinámica liberal del Estado, no siempre alejada de la corrupción, significaron un ingreso violento de los lacandones a la dinámica del mercado, un cambio significativo en sus formas de vida en general y mayores posibilidades de relacionarse con el mundo occidental. 
Una actividad que se incrementó en forma relevante a raíz de esos cambios fue el turismo en la zona arqueológica de Bonampak (consecuencia del descubrimiento de los murales), que se ubica en territorio lacandón y que trajo consigo la creación o incremento de otras labores como la producción artesanal que ahora constituye la alternativa económica más importante. Los cambios económicos y las nuevas actividades contribuyeron a la transformación de la identidad lacandona y a un acelerado deterioro ambiental.

La comunidad de Nahá (casa de agua, según sus habitantes), con una extensión de 3,848 has., dentro del área de selva protegida (flora y fauna) según el decreto federal del 23 de septiembre de 1998, cuenta con una flora de 283 especies de plantas vasculares. Entre ellas se encontró una especie nueva del género Lockhartia, tres posibles registros nuevos para México; y catorce, para la región lacandona (Durán, 1999).

De acuerdo con el Censo de 2003 de la Unidad Médica Rural, la comunidad tiene actualmente 212 habitantes, de los cuales se calcula que aproximadamente $70 \%$, en su mayoría mujeres, se ha adscrito a cultos cristianos. Sin embargo, es difícil saber con exactitud el número de conversos existente, pues cambian de religión con facilidad, dejan de asistir a los cultos o, en otros casos, prefieren no hacer comentarios sobre el tema.

\section{La trilogía religión-hombre-naturaleza}

El historiador Erick Wolf plantea que las relaciones de un fenómeno constituyen una unidad total de procesos múltiples interconectados, por lo que los empeños por descomponer en sus partes esa totalidad, falsean la realidad (Wolf, 1984). Sin embargo, esa realidad total no se nos presenta directamente, los investigadores no poseemos la facultad de penetrar directa e inmediatamente en su esencia; tenemos que dar un rodeo para poder conocer las cosas y su estructura y paradójicamente se necesita descomponer esa totalidad concreta (Kosik, 1967) para llegar a comprender la compleja realidad creada por la sociedad que se comporta con un sentido práctico de acuerdo con su cosmovisión. Conocer la cosmovisión de un grupo nos refiere permanentemente a la totalidad de su cultura. Entre los lacandones de Nahá, como entre otros grupos indígenas, su cosmovisión se basa en la trilogía religión-hombre-naturaleza, unidad inseparable que hemos considerado como un elemento básico para el análisis. Marion plantea que:

La acción del hombre sobre la naturaleza se traduce en un sistema de prácticas que funcionan como vínculo social y definen culturalmente los seres entre sí, con base en el conjunto de normas que regulan el quehacer de apropiación-extracción-transformación del medio natural. Si bien el tipo de medio ecológico en el cual se reproduce una sociedad determinará en cierta medida la práctica social de explotación del mismo, la cultura material y espiritual que se erigirá basada en dicha relación será la que, en última instancia, codificará las pautas y medidas peculiares de interacción del hombre con su medio (Marion, 1991: 19).

Así, la dicotomía naturaleza y cultura es una herramienta inadecuada para el estudio de culturas que atribuyen disposiciones y comportamientos humanos a plantas y animales, incluyendo a espíritus, monstruos, objetos, minerales y cualquier entidad, a los que atribuyen una conciencia, un alma, capacidad de comunicarse, de crecer o de morir y una conducta social basada en un código moral (Descolá, 2001).

En el caso de Nahá, todavía existen formas de una visión peculiar hombre-naturaleza-religión; entendiéndose que esa relación interdependiente afecta a dichas unidades básicas, como es la creencia de que los animales tienen personalidad propia, "el jaguar piensa como una persona, el tepezcuintle sabe orar y sabe cuando lo van a cazar y ese día cambia de camino". ${ }^{4}$ Los lacandones Perciben esa relación simbiótica como se muestra en la siguiente narración: 
Cuando Hachakyum terminó de amasar el barro, modeló sus criaturas y luego las colocó durante una noche sobre las ramas del cedro (Cedrella mexicana). El cedro árbol de dios-kuché, interviene en este insólito mito de la creación lacandona coadyuvando con su savia el despertar del pueblo de la selva (Marion, 1989: 971).

Gracias a esta relación simbiótica, Hachakyumlacandón-cedro construye representaciones mentales y formas sociales y culturales de interactuar con la naturaleza y entre las personas.

En ocasiones la naturaleza es el lugar donde interactúan los muertos. Puede ser - como entre los lacandones - la morada de seres divinizados, de personajes míticos y de las fuerzas (bienhechora o malignas) que tienen la responsabilidad y el poder de controlar la reproducción de la naturaleza y por ende de la sociedad (Marion, 1989: 971).

El término "religión" aplicado a los lacandones, no cristianizados, no es más que una abstracción de sus prácticas diarias, es sembrar maíz, curar enfermedades, cazar un venado, atraer peces, estar en el bosque, rezar en el templo tradicional, tener hijos, contar cuentos, ver un ave o un jaguar (Dichtl, 1988: 47).

Muchos investigadores del tema consideran que hay una continuidad histórica en el universo simbólico maya. Para Aída Hernández (2005), las doctrinas no son transformadoras o conservadoras en sí mismas, sino que las dinámicas históricas y espaciales de los grupos sociales le dan contenido en uno u otro sentido. La opinión de Samson es que la espiritualidad maya tradicional no es tanto un sistema de dogmas, sino más bien una espiritualidad sistémica que toca cada aspecto de la vida y construye identidades (Citado por Garrand-Burnett, 2005).

Si entendemos la identidad cultural como un sistema de creencias, un modo de sentir, comprender y actuar sobre el mundo a través de formas de vida compartidas que se expresan en instituciones, comportamientos regulados, artefactos y objetos artísticos, saberes transmitidos (Villoro, 1984), podemos advertir que, en términos generales, la identidad cultural maya en Nahá se está transformando y ajustándose a las condiciones actuales.

\section{Algunos aspectos de la religiosidad lacandona en Nahá}

Entre los numerosos trabajos etnográficos que se han escrito sobre Nahá con relación a la religiosidad, son tres los que considero más profundos: el de Alfred M. Tozzer (1902 a 1905); el de Robert D. Bruce (1953 a 1974), que recoge información de Chankín Viejo; y la investigación realizada por Marion Marie-Odile (1976 a 1999). En este apartado resumimos algunos datos de ellos y de nuestra propia investigación que sirven de marco al tema que nos ocupa.

De acuerdo con los investigadores citados, observamos que en Nahá la religiosidad está ligada a la selva, a los peñones de la orilla de los lagos, a las rocas pintadas, a las cuevas y a los templos mayas. En los relatos aún están presentes los templos de Palenque y Yaxchilán.

Los mitos narran de qué manera nacieron los dioses que a su vez dieron nacimiento a los humanos y crearon los astros para asegurar la reproducción del universo. En una primera etapa los dioses hacen intentos fallidos de crear al hombre. En una segunda etapa, los dioses establecen el orden y los lineamientos para la civilización en el mundo; luego continúan con la etapa de la creación del hombre actual, en la que los dioses se distancian y se hace necesaria la mediación de los ancianos (Bruce, 1971). El mito narra que los primeros lacandones alcanzaban a ver a todo el mundo, pero Hachakium les quitó los ojos y los tostó en un comal; y aunque se los volvió a colocar, los hombres sólo pudieron ver lo más cercano. Esto significa que en la vista está el conocimiento, la conciencia; si los hombres vieran todo, serían perfectos; los dioses necesitan seres carentes que los necesiten, que veneren y alimenten a sus creadores a cambio de la supervivencia 
que los dioses procuran. Esta idea refleja una profunda conciencia acerca de la condición humana: el hombre requiere apoyarse en seres superiores a él para aliviar su insuficiencia; si el hombre fuera perfecto, no habría dioses (De la Garza, 1989).

A lo largo del siglo XX y en la actualidad se ha preservado entre los lacandones la creencia en numerosos dioses ancestrales. Entre los principales están los tres nacidos de la flor del nardo: Hachakium, Akiantó y Sukumkium; y otro nacido de la flor nocturna, Kisin, todos con sus respectivas esposas. En una segunda categoría se encuentran Metzabok, Kanankax, Tzibataná, Kayum, Tuub, Kak y Kín. Encontramos también que siguen venerando los lugares sagrados como Metzabok, Yaxchilán, Tzibaná (en Metzabok), así como las cuevas cercanas.

En Nahá continúan fabricando sus dioses de barro que tienen forma de ollas y de incensarios que ocupan en sus ritos. Además, hacen otros incensarios pequeños con la misma forma, pero sin el simbolismo religioso para la venta. "Es para que compren los turistas. Éste sí se puede bajar al suelo porque es copia. El del templo no se puede bajar y para agarrarlo hay que lavarse bien la mano". Durante nuestra estancia en Nahá sólo pudimos tener acceso a un templo-k'unah (casa de dios) ${ }^{5}$ tradicional, reconstruido en 2002 y actualmente administrado por don Antonio Martínez, ${ }^{6}$ jefe espiritual en su comunidad que dice tener cien años, hijo de la señora Koh (Jabalí), quien se cambió de nombre por el de Petrona. El templo tiene techo de palma (kun), en el tapanco se encuentran varios pumpos (calabazos) grandes y pequeños para las tortillas y los tamales de las ceremonias. De las vigas cuelgan unas tablas aproximadamente de metro y medio de largo, donde se encuentran colocadas en hileras las ollas dios (lakilkú) de barro con rostros diferentes. De las vigas también cuelgan cáscaras de balché, maracas de morro (jícara), pequeños aros de bejuco (met) para colocar las jícaras de pozol, morrales y costales llenos de diversos objetos. En el suelo se encuentran pequeños trocitos de madera para sentarse, ollas de barro con pequeñas púas y botes de aluminio.
La cocina del templo ( $\sin$ paredes) sólo es usada para preparar la comida ceremonial, cuenta sólo con una mesa hecha de una enorme cáscara de árbol de forma cóncava, un molino de metal, trozos de madera, botes de aluminio, ánforas de plástico, una piedra de moler y los restos de una fogata. Frente a estos espacios sagrados se encuentra un cayuco de caoba para hacer el balché, bebida sagrada tradicional.

Don Antonio comentó que:

Los dioses viven en su propio mundo, mi suegro Chankín Viejo ya conoce el otro mundo, pero está aquí mismo. Antes el dios estaba presente en el templo, parecía un muchacho chiquito y hablaba con Acunchob?

En la actualidad, la mayor parte de los lacandones de Nahá no quieren hablar de la relación que guardan con los dioses por temor a que los visitantes se burlen de ellos. Para comprender la lógica lacandona es necesario tener flexibilidad y respeto por la diversidad. De acuerdo con Bruce (1967), los lacandones reconocen dos realidades distintas, saben bien que una imagen sagrada es un objeto (realidad material) que se ha hecho con las propias manos, pero a su vez es el dios (realidad espiritual). No se trata de un engaño, es otra forma de concebir la realidad. Otro ejemplo es el relato de Kayum Maax, donde cuenta que cuando el alma viaja al bajo mundo de los muertos es atacada en el camino por gallinas, piojos y perros. Además, debe cruzar un río con lagartos. Sin embargo, él sabe que los animales no pueden hacerle daño y que el río no existe, sino que es solamente el llanto de las esposas y amigos.

Don Antonio Martínez relata acerca de los dioses, que Kanancax se encarga de cuidar la montaña, los árboles, las nauyacas y toda la selva, habita cerca de la laguna de Miramar. Soustelle (1971) informa que alrededor del punto en donde se supone que Kanancax reside, la selva es inviolable. Akunchob se encarga del trabajo de las milpas, dice Don Antonio, "se le reza para que crezca 
el maíz y para que no lo tire el viento". Está casado con la señora Aknailkunchob, quien vive en Yaxchilán y cuida a las mujeres, se le reza para que nazcan rápido los niños y no queden trabados en las caderas. Hachakium también vive en Yaxchilán "el mero centro del mundo", su casa vieja fue Palenque y su último hijo se llama Tuub que vive bajo la torre que está en Palenque.

Antes en los santuarios y espacios sagrados no se podía cortar nada, ni siquiera una brizna de hierba; en la actualidad, destruir la montaña (Kax) implica recibir la ira de los dioses que la habitan y de los seres míticos que la protegen.

Los rituales se realizan para asegurar la reproducción del mundo o solicitar una buena cosecha. "A Metzabok se le reza para que llueva, para que no caigan huracanes y para que no venga la nube muy negra". También se realizan rituales para obtener una exitosa cacería, fabricar adecuadamente una herramienta o solicitar la curación de enfermedades.

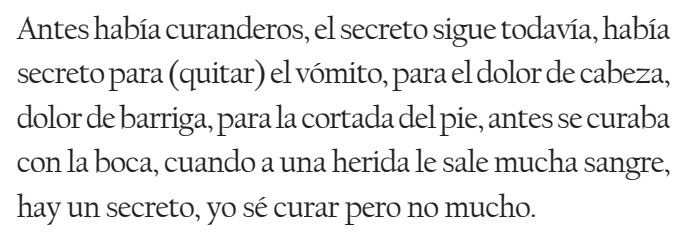

Durante los rituales de renovación de los incensarios, donde participa toda la familia, los hombres están sometidos a la abstinencia sexual, al mismo tiempo se sienten tentados por las Ixtabay (seres con aspecto femenino), que en tal caso pueden morir o provocar el fin del espacio ritual (Marion, 1994). Las mujeres no pueden entrar en el interior del templo ni participar en estos rituales que se realizan cuando florece la caoba (abril). Esto tal vez se relaciona con la consideración de que los hombres son solares y las mujeres son lunares y pueden despertar deseo (debilidad) en los hombres, factor de transformación y pérdida de energías. La mujer tiene sus propios poderes femeninos diferentes a los masculinos, tiene sus propias funciones en determinados ritos y curaciones.
Si a una persona le mordió una vez la nauyaca, le morderá tres veces más. "Es la prueba, hasta completar cuatro mordidas que tiene que recibir. Para que no suceda esto existe un secreto, tiene que pasar una hermana o la mamá tres veces sobre las piernas de la persona mordida estando acostada; ipor qué?, es un secreto que no puedo decir".

Las mujeres son las únicas que pueden ejercer ciertos poderes curativos y de protección: sólo ellas pueden preparar el k'ayem (pozol) de la ofrenda ritual al sol, conocen y recitan los rezos en los rituales. Tienen canciones para moler el maíz, hacer las tortillas, para dormir a los bebés (och-tlacuache):

Para hacerse tranquilo, ser mejor tú mismo: canción de mujer, canción de hombre. ${ }^{9}$

Las mujeres de Mateo Viejo y de Nuxi José Solórzano saben las canciones. ${ }^{10}$

También cantan cuando se toca flauta y guitarra de cuerda de ixtle o majahua y tambor de barro, dicen que se escucha en el cielo, pero quién sabe cómo se escucha, no muy fuerte pero se escucha, yo creo que es sagrado por eso se escucha. ${ }^{11}$

Las curanderas creen saber evitar las enfermedades, los malos espíritus y que el alma (pixán) abandone el cuerpo, colocando en el cuello de las personas un kuuch o cordel hilado por ellas mismas. Los cabellos y la saliva de las mujeres embarazadas son también benéficos para cierto tipo de enfermedades y para evitar que las figuras de barro se rompan al cocerlas ${ }^{12}$ "porque el ojo es fuerte"; "El marido no puede cazar animales cuando la mujer está embarazada, si lo hace morirían madre e hijo porque la carga es muy fuerte". ${ }^{3}$

En Nahá se casan entre los 14 y 15 años ${ }^{14}$ de edad y se percibe una mezcla de apellidos y nombres españoles y una continuidad de nombres tradicionales. ${ }^{15}$

De acuerdo con el censo de la Unidad Medica Rural de 2003, de 84 niños nacidos entre 1990 a 2003, siete (8\%) de ellos conservan dos nombres mayas, 42 (50\%) tienen 
un solo nombre maya, 22 (26\%) no conservan nombres ni apellidos mayas, ocho (10\%) tienen un nombre en maya y un concepto en español usado como apellido, tres (4\%) son recién nacidos sin nombres y dos (2\%) utilizan conceptos del español como apellidos; en términos generales puede decirse que existe una leve continuidad de nombres mayas lacandones en Nahá.

\section{La relación hombres-naturaleza}

Como ya se apuntó, la cosmovisión lacandona en Nahá guarda una estrecha intersubjetividad entre hombres, naturaleza y dioses, que mantiene el equilibrio necesario para el funcionamiento y reproducción de la naturaleza y del orden del universo simbolizado, socialmente construido por esa cultura. Así, como dice Lenkersdorf para otros grupos indígenas (1996), en la naturaleza humanizada de Nahá, no hay objetos, no aparecen ni en el idioma, ni en otros ámbitos de la cultura, porque no hay nada que no tenga corazón; y si tiene corazón, vive, tiene pensamiento y es sujeto. Como entre otros pueblos indígenas americanos, se atribuyen posiciones y comportamientos humanos a plantas, animales, objetos y minerales. Estas entidades están dotadas de un alma, una capacidad de comunicarse y una conducta social, "las distinciones entre seres vivientes y objetos parecen borrosas" (Descolá, 2001: 101).

Al respecto, Kayum Mario Maax nos dijo que "algunos animales saben orar (rezar y cantar), el tigre cuando nos ve y lo vemos nos pesa (paraliza), no podemos gritar, no sale nuestro grito y cuando sale, el tigre ya se fue".16 Esto quizás se asocie a esa humanización mencionada o a la creencia de que los animales tienen un dios protector. Los árboles y las plantas también tienen características humanas y sexo; por ejemplo, los papayos y papayas, los ceibos y las ceibas y las semillas como la del colorín (ham) que son para los collares: "las semillas rojas chicas son mujeres y cuesta mucho abrirles el hoyito, las semillas de dos colores, rojo y negro son más grandes y son hombres". También son masculinos el poniente, el día, la sequía, la luz, la vida pública, las hormigas, el maíz y la sabiduría, en tanto que son femeninos el oriente, la noche, la lluvia, las tinieblas, la vida doméstica, las serpientes; la adivinación es tejedora de vida (Marion, 2000).

La interrelación lacandones-naturaleza, en el caso de los animales, es quizás más profunda que con las plantas y tiene características especiales. Una de ellas es que se da en forma personalizada a través del animal que es su onen o inyonen (literalmente mi pariente), que puede ser mono, jabalí, venado, tigre, faisán, tepezcuinte, comadreja, guacamaya o paloma, pero dotado, según Bruce (1971), de un alma inmortal.

Cada lacandona o lacandón está asociado con su onen a través de los sueños (wayak-ver o soñar), donde "el uno se representa al otro". Esta relación también refiere a las deidades: las personas fueron creadas por el dios Hachakium y los animales onen por Kisin, dioses antagónicos relacionados con el día y la noche, pero en la relación lacandón -onen tienen un acercamiento mediante los sueños.

\section{Dualidad hombre-animal (Vínculo entre los dioses antagónicos)}

El onen también puede aparecer durante un sueño, para advertir a la persona que corre algún peligro o que recibirá una visita (Marion, 1991). Actualmente, entre los lacandones el onen parece ser una especie de simbolismo de linajel7 (patrilineal) que delimita la endogamia tradicional (Bruce, 1971). En Nahá habitan los miembros de los linaje $k^{\prime}$ eken y maax que intercambian sus mujeres.18 La mayoría de los nombres19 de las personas están acompañados del nombre del animal (onen) de su linaje: Maax-mono y Koh-jabalí. Es importante mencionar que a muchos se les ha impuesto nombres en español por las instituciones y los visitantes (Villa Rojas, 1967). Para 2003, según el Censo de la Unidad Médica Rural, de 84 niños de 0 a 13 años sólo siete tenían dos nombres mayas, como era la costumbre tradicional 
(el del orden de su nacimiento en la familia y el de su linaje); la mitad tenía sólo un nombre maya (el de su linaje, generalmente); pero casi la cuarta parte (22) ya no llevaba ningún nombre maya.

\begin{tabular}{|l|c|c|}
\cline { 2 - 3 } $\begin{array}{l}\text { Hombres } \\
\text { Creados por Hachakium }\end{array}$ & $\begin{array}{l}\text { Sueño } \\
\text { (Vínculo entre Hombre y animal) }\end{array}$ & $\begin{array}{l}\text { Animales-onen } \\
\text { Creados por Kisin }\end{array}$ \\
\cline { 2 - 3 } & \\
\hline
\end{tabular}

La relación entre los lacandones y su onen es una muestra de cómo los mitos y creencias funcionan como reguladoras de la existencia, las relaciones sociales y la protección de la naturaleza. Entre ellos, al ser "parientes" se establece una relación sinérgica que varía del respeto-aceptación-protección a la depredación necesaria para la sobrevivencia de animales y humanos. Los hombres pueden comer animales de su propio onen. Soustelle menciona el caso de un miembro del linaje maax a quien encontró comiendo mono; al preguntarle si eso era posible, el hombre contestó riendo: "es verdad que es mi pariente, pero de todos modos me los como" (citado por Villa Rojas, 1967:480). Pero lo que se toma de la naturaleza debe ser lo indispensable para vivir, "creen que si desperdician la carne, la caza no va a aparecer, en consecuencia están acostumbrados a no matar o cortar más de lo que necesiten para comer, no dejan nunca que la caza se pudra en la selva" (Baer, 1981: 169). También hay prohibiciones reguladoras, "no se debe matar el pájaro cuclillo-ch'icbur (Crotophiga Sulcirostris), dicen que si un hombre mata a uno de estos, a su hijo se le caerá el pelo" (Baer, 1981: 248).

Pero en todo caso las relaciones entre el onen y la persona son muy profundas, pues cuando su animal onen es herido en el mundo de los sueños, el hombre despertará adolorido o enfermo; o bien no se levantará jamás (Marion, 1996). Respecto a esa relación, Kayum Maax me narró la creencia según la cual "después de la muerte volveremos a vivir en forma de animales y los animales lo harán en forma de hombres y nos maltratarán como nosotros hacemos ahora con los animales, por eso no hay que maltratarlos porque son como nosotros".
Otro elemento regulador de la conducta en actividades como la caza, la pesca y la tala de árboles, es la creencia en un espacio poblado de seres fantásticos que los amenazan cuando se violan las normas (Kanankax, Yumkax, el Sombrerito y las Ixtabay). Los lacandones, como otros pueblos de la región, saben que la selva está protegida por el Señor del bosque, quien cuida a sus animales de la depredación humana. ${ }^{21}$

Como señala Descolá (2001), las relaciones con la naturaleza pueden ser de reciprocidad en tanto que los humanos tienen una deuda con los no humanos por los alimentos que éstos les proporcionan, hay un intercambio de servicios. Las relaciones son de protección, cuando los animales o plantas son sacralizados y son percibidos como dependientes de los humanos; pero son de rapacidad cuando, por ejemplo, hay una venganza de parte del dueño de los animales quien castiga a los cazadores por no ofrecer un equivalente por la vida quitada (Descolá, 2001).

Aunque los habitantes de Nahá aún siguen los signos de la naturaleza en sus actividades y las normas de conducta fijadas por su cosmovisión, también se observan relaciones de rapacidad. Los mitos relatan cómo algunos, después de matar a muchos animales, fueron obligados a casarse con los animales y cuidarlos, hasta haber logrado regenerar la población diezmada. ${ }^{22}$

En ese aspecto observamos que existen especies con las cuales las relaciones han sido incorrectas o burdas; un caso es la caza inmoderada de loros, como consecuencia de la gran cantidad de flechas que se producen para la venta y las cuales requieren plumas de estas aves. De acuerdo con Miguel García, habitante de Nahá, una persona podría llegar a cazar hasta 20 loros diarios con su rifle, pero si son muchas las personas pueden cazar hasta 300 loros diarios. La caza se realiza sólo durante dos meses al año.

Con la modernidad, ha aumentado en Nahá la necesidad de tener dinero; con ello han sido producidos cambios en los valores y creencias tradicionales, lo que ha redundado en una rapacidad hacia la naturaleza. 
Pero como dijimos al principio, en esa transformación de valores y normas culturales también ha incidido el cristianismo implantado en la región.

\section{La visión cristiana en Nahá y sus efectos en la ecología}

La presencia del pensamiento occidental a través de los cultos cristianos, en Nahá, se da en dos etapas; la primera fue promovida por los misioneros estadounidenses del Instituto Lingüístico de Verano (ILV) Phillipe Baer y su esposa, quienes llegaron en enero de 1944; la segunda ha sido realizada por pastores tzeltales de poblados vecinos a partir de la década de los noventa.

Tanto en los valores, simbolismos y concepciones, las distancias entre las dos cosmovisiones son muy grandes, variadas y de consecuencias muy complejas. Por razones obvias en este apartado sólo comparamos algunos elementos de los mitos de la creación de ambas tradiciones, para tener una idea de la dimensión de los cambios, en Nahá, que han acarreado algunos cultos cristianos en la relación-hombre naturaleza.

En las creencias occidentales se aprecia una relación vertical y de sometimiento de la naturaleza por el hombre, quien se asigna una categoría superior a la de los animales y todo lo existente en la naturaleza, como se aprecia en el siguiente relato bíblico (Génesis capítulo 3, 5). Después de la creación, el Dios único, infalible y todopoderoso dice a Adán y Eva:

Crezcan, multiplíquense y pueblen la tierra. Que teman y tiemblen ante ustedes todos los animales de la tierra y todas las aves del cielo. Pongo a su disposición cuanto se mueve sobre la tierra y todos los peces del mar (Biblia Latinoamericana).

Los parámetros verticalistas y jerárquicos del cristianismo contrastan con la intersubjetividad horizontal de los lacandones que considera, como vimos, que todo lo que existe - personas, animales, recursos naturales y dioses - tiene vida y posiciones, relaciones y conductas equiparables y complementarias, ${ }^{24}$ como lo expresa el anciano Chankín Viejo:

Todos los seres vivientes estamos relacionados, amarrados de la misma raíz. Cuando Hachakium hizo las estrellas, las hizo de arena y piedras y las sembró. Las raíces de cada estrella son las raíces de un árbol; cuando se cae un árbol, una estrella cae del cielo. ${ }^{25}$

Otro mito relata que cuando Hachakium terminó de modelar a los hombres de barro - menos los dientes que fueron hechos de maíz-, los colocó durante una noche sobre las ramas de un cedro (kuché-árbol dios), quien con su misma sangre (savia) ayudó al despertar de los lacandones (Marion, 1989). Después, al tallarse las manos, los rollos y fragmentos de arcilla cobraron vida al caer a la tierra, volviéndose culebras, hormigas, alacranes, gusanos, zancudos, mosquitos y todo género de bichos (Bruce, 1971).

En el relato bíblico de la creación, hombres, animales y plantas tienen orígenes y valores distintos. Además, el árbol del jardín, la serpiente y la mujer (prohibición, tentación y pecado) son causantes de la imperfección en la humanidad. Como consecuencia de esta relación discriminatoria surgida en el inicio de los tiempos, Dios culpa a la mujer-víbora y la sentencia: "maldita seas entre todas las bestias y entre todos los animales del campo [...] haré que haya enemistad entre tú (serpiente) y la mujer, entre tu descendencia y la suya [...] (le dijo a la serpiente); multiplicaré (mujer) tus sufrimientos en los embarazos [...] necesitarás a tu marido y él te dominará, por haber escuchado la voz de tu mujer[...] maldita sea la tierra por tu culpa (al hombre)" y fueron echados del jardín del Edén (Génesis, capítulo 3).

La religión cristiana es antropocéntrica, hay una dualidad polarizada entre lo humano y la naturaleza. El hombre/mujer es creado a imagen y semejanza de Dios, sin considerar al resto de la naturaleza. La tierra 
no tiene otra finalidad que servir al ser humano en una relación de dominio y de sujeción. Animales y plantas carecen de alma, al carecer de alma y corazón, no sienten ni tienen vida, son objetos y el hombre puede dominarlos. La divinidad monoteísta no tiene guardianes que cuiden la población animal y vegetal de la depredación del hombre. Los mitos no fungen como reguladores de sus relaciones: los seres fantásticos (ángeles) protegen a Dios y al hombre, no a la naturaleza.

El principio creador femenino del universo no es partícipe en la creación del mundo. En las concepciones cristianas, la mujer desempeña un rol subordinado ante el hombre; la parte masculina crea y ordena el universo. Por ser ella la causante del pecado del hombre, al contrario de lo que ocurre en la cultura lacandona, ${ }^{26}$ no participa en los rituales sagrados y cuando es virgen se convierte en botín de guerra:

Moisés se enojó contra los jefes de las tropas que volvían del combate (de la guerra santa) [...]. Moisés les dijo: ¿Así pues han dejado con vida a todas las mujeres? [...] maten pues. A todos los niños hombres $\mathrm{y}$ a toda mujer que haya tenido relaciones con un hombre, pero dejen con vida y tomen para ustedes a todas las niñas que todavía no han tenido relaciones (Números 31, 13-18).

El historiador Lynn White sostiene que al destruir el animismo pagano, el monoteísmo judeo-cristiano hizo posible la explotación de la naturaleza; la despojó de su carácter sagrado, la hizo profana. Lo sagrado, como todavía se concibe en Nahá, era un freno la depredación humana. "La victoria del cristianismo sobre el paganismo fue la revolución psíquica más grande en la historia de nuestra cultura" (Álvarez, 1993: 165), pues transformó la visión del hombre sobre el cosmos.

Por otra parte, la religiosidad lacandona imagina un cosmos amenazado de destrucción, cuyo equilibrio están obligados a mantener las personas a través de los rituales con ofrendas de pozol e incienso. Mientras que en la vi- sión mecánica, occidental (Bacón, Descartes y Leibniz), el mundo es como un gigantesco reloj puesto en movimiento por el creador (Álvarez, 1993: 164). La misión del hombre consiste en perfeccionar la naturaleza, descubrir sus secretos por medio de instrumentos cuantitativos y experimentales y ponerlos al servicio del progreso, en beneficio de los sectores sociales hegemónicos.

A los animales se les puede matar incluso por deporte o diversión; ${ }^{27}$ como la matanza de lagartos y otros mamíferos realizada en la región lacandona por visitantes en la década de los treinta (Soustelle, 1971). Con la misma dinámica depredadora, en los siglos pasados, muchos árboles sagrados como las ceibas (yaxché) fueron cortados por sacerdotes católicos (Hernández, 1997) por motivos ideológicos, además, otras especies de árboles fueron taladas para madera y cortadas por chicleros y modernos empresarios.

Durante la estancia de Baer en la selva lacandona, la ideología cristiana y la modernización iniciaron su presencia en Nahá, Baer construyó una casa con planta de luz eléctrica y una pequeña tienda donde repartía víveres, medicinas, armas y herramientas de metal. Al mismo tiempo que aprendía la lengua y las tradiciones de los lacandones, les enseñaba a leer. También escribió algunos libros apoyado por instituciones de Estados Unidos. Pero su labor fundamental fue la evangelización realizada con su equipo de misioneros a través de un show de transparencias e imponiendo nuevas reglas: prohibieron el cultivo del tabaco ritual, el consumo de especies animales y la preparación del balché (Baer, 1981; De Vos, 2002). Durante este proceso, algunos elementos de la religiosidad lacandona se mezclaron con elementos de la visión occidental cristiana.

Después de 15 años de evangelización en Nahá, los misioneros reconocieron que su lucha era casi inútil; el único éxito de Baer, de acuerdo conBruce (1968), fue que los lacandones creyeran que Jesucristo podría ser el nombre castellano de algún hijo de Akiantó, el Dios del comercio y de los extranjeros, creencia que sigue presente en la actualidad. 
En la década de los noventa se inicia otra campaña proselitista, con pastores evangélicos tzeltales de las comunidades vecinas, que ha obtenido mejores resultados. De acuerdo con Miguel García, ${ }^{29}$ en Nahá hay desde 1994, misioneros indígenas presbiterianos que dan servicio en tres templos; una familia adventista del séptimo día; varios misioneros pentecostales y bautistas que llegaron en 1995 y continúan llegando misioneros de otras religiones. Tres de estos cultos enseñan totalmente en maya lacandón, los demás lo hacen con ayuda de traductores.

Las primeras cristianas de Nahá fueron en su mayoría mujeres adultas de origen tzeltal y chol, quienes han tenido un papel fundamental en la conversión de sus esposos e hijos lacandones por sus creencias traídas de sus comunidades de origen.

La renuencia que los lacandones mostraron hacia la evangelización impartida por los Baer (estadounidenses) fue suavizada en la ultima década por los pastores tzeltales y las mujeres (esposas) tzeltales y choles quienes han aprendido la lengua maya además del español, tienen una cultura similar y comparten la misma selva. Es de suponerse que su visión reflejada en la enseñanza de la Biblia funcione como un factor positivo en la difícil cristianización de los lacandones: "es difícil lograr la conversión de un lacandón, en Metzabok la religión no les entra, son muy borrachos, todavía no les ha llegado sus tiempo a esos hermanos" opina el pastor tzeltal Leonardo Vázquez Guzmán, de Nahá. ${ }^{30}$

Esta resistencia se manifiesta con la presencia de elementos de la religiosidad lacandona en los conversos, como en los espacios separados para hombres y mujeres durante los cultos que realizan en el interior de las casas que fungen como templos evangélicos. ${ }^{31}$ En Nahá, la tradición de que hombres y mujeres tengan espacios separados tiene su origen en los mitos de la creación y se practica en diversos espacios, incluidas las asambleas de la comunidad, y otros espacios de discusión donde pueden participar solamente hombres o solamente mujeres. "En las asambleas los hombres y las mujeres no pueden participar juntos, porque es aparte, si quieren una cosa las mujeres tienen que tomar ellas sus propios acuerdos". 32

A diferencia de Lacanhá, en donde los antiguos y semidispersos caribales lacandones (familias extensas y poligínicas, que formaban una unidad en torno al jefe de la familia) se refuncionalizaron convirtiéndose en los siete barrios actuales (Marion, 1991), en Nahá, reubicada en un pequeño valle rodeado de montañas, que no cuenta con el espacio requerido para que hubieran sido establecidos los antiguos caribales, podemos suponer que los caribales se han ido refuncionalizando a través de los ocho grupos religiosos que existen en la comunidad, tomando en cuenta que los conversos de cada culto están unidos por el parentesco.

Como en otros grupos indígenas, uno de los motivos importantes para la conversión se relaciona con la posibilidad de que los hombres dejen de consumir alcohol. Kín, hijo de Mateo (evangélico), comentó que a los 18 años comenzó a tomar mucha caña (aguardiente) "pero conocí a Jesús y ya no tomo, ni veo tele, viendo a las mujeres en la tele puedo desearlas y pecar".

Los aparatos electrónicos y otros productos hechos por la cultura occidental dicen que pertenecen al dios de los extranjeros Akiantó, a este dios le adjudican la construcción de fábricas, entre otros. "Akiantó dios de los extranjeros, es dueño de las fábricas, los aparatos eléctricos, las bombas, aviones y refrescos. A él le gustan las mujeres desnudas, a los lacandones no les gusta que las mujeres se vean así". ${ }^{33}$

La señora Estela Solórzano Koh (evangélica) narra como "el Kisin obliga a mi esposo a tomar matacaña (aguardiente)". Aquí nuevamente se relacionan el alcohol con el dios Kisin, demostrándonos que, aun entre los evangelizados, sigue la creencia en el dios Kisin, el dios del temblor, algunas personas lo traducen como el diablo de la cultura occidental. Sin embargo, en la visión tradicional tiene características muy distintas; también creen que Jesucristo es algún hijo de Akiantó, el dios de los extranjeros. 
Otros elementos que contribuyen a la transformación de la religiosidad en Nahá son la disminución de árboles de pino, necesarios para la recolección de resina para el incienso, escasez de la miel silvestre —elemento básico en la producción de la bebida ritual del árbol del balchéasí como la falta de recursos económicos para comprar los ingredientes de la comida, ${ }^{34}$ consistente en tamales y grandes cantidades de pozol y balché. Bor Maax hace referencia a su resistencia a la cristianización:

Yo, de mi parte todavía no he aceptado la Biblia. Mi papá (Chankín Viejo) dijo que no podemos decir que [los nuestros] no son dios, porque la Biblia es Jesucristo, (ahí) sabemos que es un dios grande; [pero] también lo que tengo yo, también es dios Hachakium, pero de los lacandones.

$Y$ añade: Los misioneros ${ }^{35}$ dicen que nuestros dioses, no son dioses que son diablos, son Satanás, pero no son, son mi costumbre, mi tradición y no lo puedo dejar. Ahora nada más Antonio Martínez y mi hermano Chankín tienen sus dioses, tienen sus templos y hacen sus fiestas. ${ }^{36}$

\section{Conclusiones}

De acuerdo con el trabajo de campo que realicé en Nahá y a las etnografías de los autores citados, considero que los evangelizados de Nahá tienen características peculiares que nos permiten cuestionar su verdadera adopción del cristianismo y plantearnos más bien que algunos elementos cristianos re-significados se van incorporando a la cosmovisión y tradiciones lacandonas, ya que:

i. Sigue proliferando la cosmovisión tradicional entre la generación joven y los conversos cambian de una religión a otra con gran facilidad (Dichtl, 1988).

ii. Entre los convertidos no han disminuido las familias poligínicas (Marion, 1991).

iii. Las esposas tzeltales son quienes han contribuido a la conversión de su esposo e hijos. iv. La predicación es llevada a cabo por pastores tzeltales, quienes llegan procedentes de comunidades vecinas, no son lacandones. Los cultos realizados los sábados y domingos son acoplados a los quehaceres cotidianos.

v. Al escuchar las conversaciones de los evangélicos podemos percibir en sus discursos muchos elementos de la religiosidad tradicional, como es el caso de las frases: "el tepezcuinte sabe orar", "el tigre piensa como lo hace una persona"; o las frecuentes referencias al dueño de la montaña (Kanankax y El Sombrerito o Sombrerón), su creencia en la naturaleza sexuada y en la forma de trabajar la tierra, así como la experiencia onírica que todavía es muy importante para ellos.

vi. Existe resistencia masculina a aceptar el culto cristiano de sus esposas tzeltales o choles.

La relación tradicional hombre-naturaleza de los lacandones de Nahá se transforma cada día en otra más occidental y depredadora como consecuencia de múltiples procesos acontecidos durante el siglo XX en la region: explotación maderera, dotación ejidal, integración a la dinámica mercantil, migración indígena, mercado de xate, ganadería, agricultura extensiva, presencia de instituciones oficiales y la llegada de nuevas creencias religiosas. En el aspecto religioso, muchos elementos cristianos son incorporados o resignificados dentro del contexto tradicional, como por ejemplo la creencia de que Jesucristo es algún hijo de Akiantó, el dios del comercio y los extranjeros; y que Kisin, el dios del temblor, es el Diablo. ${ }^{37}$

Para detener el deterioro ambiental de la selva considero que es necesario y urgente motivar a las generaciones jóvenes lacandonas y de otros grupos para que rescaten y fortalezcan la relación hombre-naturaleza de los pueblos mayas. Es necesario y urgente revertir la relación depredadora, grosera y abusiva que tiene nuestra sociedad hacia la naturaleza. Relación que se ha extendido de diversas formas hacia la selva como una respuesta en la práctica cotidiana, a la crisis actual. 
Retomando las palabras de la antropóloga Dichtl Sigrid, no se trata de buscar un retorno romántico al pasado sino de buscar un nuevo camino, que sea transitable a partir de las actuales condiciones tanto ecológicas como socioculturales, no se trata de regresar a las costumbres antiguas no aplicables a nuestro contexto.

¿Por qué recuperar parte de la cultura tradicional de Nahá? El antropólogo costarricense Gerardo Alfaro señala que recuperar prácticas tradicionales puede ser una alternativa, una respuesta a la crisis ambiental, económica y social actual.

La práctica de las técnicas y conocimientos ancestrales sobre las especies vegetales alimenticias "sólo se puede lograr recuperando de la mente de los abuelos ese caudal de sabidurías ancestrales y de sus prácticas etnoecológicas para tener una mejor calidad de vida". Esta forma de vida sólo podrá retomarse si interpretamos esos elementos simbólicos olvidados, conociendo sus significados y usos y que aún se encuentran vivos en las memorias de sus descendientes a través de la oralidad.

Será necesario cuestionar la viabilidad y sustentabilidad de actividades modernas como la ganadería y la agricultura extensiva. De acuerdo con Angélica Inda (1983) la superficie mínima talada por escasos ganaderos y madereros (1983) era de 98\% contra 2\% de de la milpa de los campesinos.

Entre los lacandones de Nahá, las posibles alternativas podrían ser, por ejemplo, la implementación del cultivo diversificado de plantas de uso tradicional; promover la manufactura de diversos artículos artesanales ornamentales o de uso cotidiano que puedan comercializarse con materiales obtenidos de la misma selva y recuperar las técnicas textiles de trabajo con la majahua, tintes naturales, entre otros.

Marion decía que "al desaparecer el mundo donde se albergan las representaciones mentales del universo fantasmagórico lacandón, desaparecerá una forma de vivir, de pensar y de reproducirse" (Marion, 1991: 262). Sin embargo, es posible que también al desaparecer las representaciones mentales del universo lacandón o de los pueblos mayas, es decir esa forma de ver el universo, esa abstracción de las prácticas diarias, esa forma de vivir de pensar y de reproducirse, se contribuirá también a la desaparición del espacio selvático.

\section{Notas}

${ }^{1}$ Este artículo, surge de mi tesis de licenciatura en Antropología Social denominada "El sustrato religioso lacandón en relación con los diversos cultos cristianos en Nahá, municipio de Ocosingo, Chiapas", UNACH, enero de 2008.

${ }^{2}$ Nahá y Metzabok son incluidas en 1975 por lo que el parque nacional se extendió a más de 662000 Has. de acuerdo con Nations, 1978.

${ }^{3}$ En agosto de ese año cada lacandón casado había recibido 4,862.90 pesos por pagos de madera, para noviembre otros 6060.50 pesos, y se les prometió que los pagos continuarían.

${ }^{4}$ Conversación con Kayum Mario Maax, 10/12/2004.

${ }^{5}$ Nuxi Solórzano y Chankín Mario comentaron que Mateo y Chankín García tienen sus propios templos.

${ }^{6}$ Nació en Monte Líbano (Puná) y ha vivido en Taniperlas, Miramar, Santo Domingo y Laguna Culebra..

${ }^{7}$ Otros habitantes también mencionaron que antes se podía hablar personalmente con el Dios.

${ }^{8}$ Conversación con Atanasio Chankín, 18/12/2004.

${ }^{9}$ Conversación audiograbada con Kayum Maax, 21/12/2004.

${ }^{10}$ Conversación audiograbada con Kín García Martínez, 21/12/2004.

"Conversación audiograbada con Kayum Maax, 21/12/2004

${ }^{12}$ La investigadora Marion afirma que la mayoría de los investigadores tienden a ocultar el papel femenino (1988: 52), y hasta hay quienes presuponen un machismo lacandón tal como en la cultura occidental, basándose en la compra de la novia, que ni es novia ni es compra.

${ }^{13}$ Conversación con Kayum Mario Maax, habitante de Nahá, 10/12/2004.

${ }^{14}$ Información de María Hernández, enfermera auxiliar de la clínica de la Unidad Médica Rural, en diciembre de 2005. 
${ }^{15}$ Fenómeno parecido ocurre con el uso de la vestimenta e idioma.

${ }^{16}$ Una historia similar fue contada también por Lucas, habitante de Lacanhá Chansayab: "el tigre piensa como lo hace un hombre, una vez vi al tigre y me pesó (paralizó), nos quedamos viendo y no pude gritar ni correr, después el tigre dio un gran salto y se perdió en la selva, entonces sí pude correr y gritar" (10/12/2004).

${ }^{17}$ Grupo de personas que traza su descendencia a través de una sola línea a partir de un ancestro común.

${ }^{18}$ Citado por Marion (1991: 38), recopilado por Boremanse en 1986.

${ }^{19}$ Los nombres de los lacandones son pocos e indican el orden de nacimiento entre los hijos de una misma familia; al hijo mayor se le llama Kín-sol, con el segundo Kayum-dios del canto, al siguiente Chankín- pequeño sol, Bor-abeja y para las mujeres Nakín, Nachankín, Nakayum, Nabor, Koh, Nuk y Chanuk. De acuerdo al censo mencionado, 40 personas tienen nombre Chankín, 21 se llaman Kayum, 17 Chanuk, 12 Bor, 10 Nuk, 9 Koh, 9 María, 7 José, 6 Kín, 2 Chambor, también acostumbran cambiarse de nombre cuando quieren.

${ }^{20}$ En Nueva Palestina, un campesino nos relató sus múltiples experiencias con El Sombrerito, el dueño de los animales, un ser de pequeña estatura que hace que los cazadores se pierdan en la montaña (notas de Campo, diciembre de 2005).

${ }^{21}$ Los mitos que relatan estas relaciones de humanos con animales (zopilota, perro, mono, pecarí, jaguar y tuza), fueron recopilados en Nahá y Lacanhá por Boremanse en 1984.

${ }^{22}$ Boremanse (1984: 230) recopila un mito donde se narra que las calabazas son hijas de un hombre y una zopilota.

${ }^{23}$ Frase recopilada por Bruce y Duby, también se puede escuchar en una entrevista con Chankín Viejo, en video documental de Garrik Wilkie Film 2005 "Chankín Viejo: El Sabio de la Selva Lacandona”.

${ }^{24}$ Sobre el poder femenino en la cultura lacandona, véase los artículos de Marion, "La dimensión de lo invisible", 1988 y "Una práctica insólita de poder", 1992, compárese con la Biblia en Dt. 24, 1; Ec. 25, Pro. 7, 5-27.
${ }^{25}$ Actividades como la pelea de gallos, el toreo o la pesca deportiva.

${ }^{26} \mathrm{Habitante}$ de Nahá, conversación realizada el 10/12/2004.

${ }^{27}$ Conversación realizada el 20/12/2004; Nations (1978) 29 años atrás menciona que todas las familias de Metzabok se habían convertido a la religión adventista del séptimo día, menos una.

${ }^{28}$ En el interior del templo presbiteriano de don Kín García, durante el culto me había sentado sin darme cuenta en el espacio femenino, al lado de mi compañera de trabajo, y los niños se reían; uno de ellos se acercó a decirme que debía sentarme junto con los hombres; las mujeres me veían y se reían.

${ }^{29}$ Conversación audiograbada con Kín García Martínez, 21/12/2004.

${ }^{30}$ Conversación audiograbada con don Antonio Martínez, 22/12/2004.

${ }^{31}$ Los tamales se hacían de carne de mono y de faisán, las que han sido sustituidas por carne de guajolote; la miel se ha sustituido por azúcar o panela.

${ }^{32}$ Un sacerdote católico que llegó con una de las compañías madereras culpó a los dioses lacandones de las epidemias de paludismo y gripes que asolaba la región (Duby, 1961: 37).

${ }^{33}$ Conversación con Bor Maax el 22/12/2004, una historia similar fue narrada por Pepe Camacho Kín.

${ }^{34}$ En Nueva Palestina, Ocosingo, pudimos escuchar del campesino presbiteriano Pedro Hernández que los judíos habían construido las pirámides de Chetumal, ubicadas cerca del poblado.

\section{Bibliografía}

Álvarez, Andrés, 1993, "iEs la Religión judeo-cristiana responsable de la crisis ecológica?", en Iztapalapa, humanismo y Naturaleza, núm. 31, año 13, México, pp. 163-180.

Baer, Phillipe y R. Merrifield William, 1981, Los lacandones de México Dos estudios, INI-Serie Antropología SocialSEP, México.

138 Revista LiminaR. Estudios sociales y humanísticos, año 6, vol. VI, núm. 1, junio de 2008, Tuxtla Gutiérrez, Chiapas. ISSN: 1665-8027 
Boremanse, Didier, 1991, "Magia y Taxonomía en la etnomedicina lacandona", en Revista Española de Antropología Americana, Facultad de Geografía e Historia, Universidad Complutense de Madrid, núm. 21, España, pp. 279-294.

—, 1984, "Mitología y organización social entre los lacandones (hach winik) de la selva Chiapaneca", en Estudios de Cultura Maya, (coord.), Mercedes de la Garza UNAM, Vol. XV, México, pp. 225-249.

Bruce, S, Robert, 1968, Gramática del lacandón, INAH-SEP, Departamento de Investigaciones Antropológicas, Publicación 21, México.

—, 1967, Jerarquía maya entre los dioses lacandones, Anales del Instituto Nacional de Antropología e Historia, vol. 18, México.

Bruce, S, Rober, Carlos U. Robles, Enriqueta Ramos (et. al.), 1971, Los lacandones 2, Cosmovisión maya, INAH-SEP, núm. 26, México.

Censo de La Unidad Medica Rural (UMR) de la comunidad Nahá de 2003.

De la Garza, Mercedes, 1989, "Cosmogonía de los lacandones actuales”, en Mitos cosmogónicos del México indígena, (Coord) Jesús Monjarás, Colección Biblioteca INAH, México, primera reimpresión, pp. 60-73.

De Vos, Jan, 2002, Una Tierra para Sembrar Sueños, Fondo de Cultura Económica/CIESAS, México.

Descolá, Philippe, 2001, Naturaleza y sociedad, perspectivas antropológicas, Siglo XXI, México.

Dichtl, Sigrid, 1988, Cae una Estrella. Desarrollo y destrucción de la selva lacandona, SEP-FRONTERAS, México.

Duby G. y Blom, F., 1955, La Selva Lacandona, Cultura, vol. I, II, México.

Duby, Gertrude, 1961, Chiapas indígena, UNAM, México.

—, 1993, Los Lacandones: Su pasado y su presente, en Homenaje a Alfonso Villa Rojas, Antropología Mesoamericana, (Comp.), Víctor Manuel Esponda Jimeno, Sophía Pincemin Deliberos y Mauricio Rosas kifuri, Serie Nuestros Pueblos, DIF-Chiapas, Tuxtla Gutiérrez, Chiapas, pp. 407-414.

Durán, Alejandro, 1999, La estructura y etnobotánica de la selva alta perennifolia de Nahá, Chiapas, tesis de maestría, UNAM, México.
Erosa, Enrique, 1994, Los lacandones (versión preliminar), INI, México.

Flora y fauna, en: www.mundochiapas.com/turismo/reservas/mazules.html.

Garrand-Burnett, Virginia, 2005, "Inculturación de la teología protestante en Guatemala", en Protestantismo en el mundo maya contemporáneo, (editores), Mario Humberto Ruz y Carlos Garma, UNAM-UAM, México. núm. 30, pp. 49-64.

Hernández, Elisa, 1997, "La Ceiba”, en Arqueología Mexicana, vol. V, núm. 28, México, pp. 68-73.

Hernández, Rosalva Aída, 2005, "Protestantismo, identidad y poder entre los mayas de Chiapas", en Protestantismo en el mundo maya contemporáneo, (editores), Mario Humberto Ruz y Carlos Garma, UNAM-UAM, núm. 30, México, pp. 99-128.

Inda, Angélica, 1985, Nueva luz sobre los lacandones, Boletín del Archivo Histórico Diocesano, INAREMAC, 2(5-6):1-75, SCLC, Chiapas.

La Biblia Latinoamericana (católica), 1986, Edición Paulinas, edición 17, Madrid.

Lazcano, Marco A. et. al., 1992, "Importancia y situación actual de la selva lacandona: perspectivas para su conservación", en Reserva de la Biosfera Montes Azules, Selva Lacandona: Investigación para su Conservación, (editores) Ramos, Olmos, Mario Vázquez, Exosfera, núm. 1, México, pp. 393-408.

Lenkersdorf, Carlos, 1996, Los hombres verdaderos. Voces y testimonios tojolobales, Siglo XXI, México.

Marion, Marie-Odile, 2000, "Bajo la Gran Ceiba: la cosmovisión de los lacandones”, en Desacatos. La cosmovisión de los grupos actuales de México, CIESAS, núm. 5, México, pp. 45-56.

—, 1989, "El hombre y la madera: un intento de sistematización”, en II Coloquio Internacional de Mayistas, Memorias, 2, UNAM, México, pp. 963-973

- 1994, Fiestas de los pueblos indígenas, identidad y ritualidad entre los mayas, INI, México.

—, 1988, "La dominación de la naturaleza", en Medio ambiente y comunidades indígenas del sureste, (Comp.), R. Uribe Iniesta, UNESCO, Villahermosa, Tabasco, pp. 17-32. 
—, 1997, "La oniromancia maya: un recurso ante el infortunio", en Anuario, CESMECA-UNICACH, Tuxtla Gutiérrez, Chiapas, México, pp. 69-105.

-, 1991, Los hombres de la selva, CONACULTA-INAH, México.

_, 1992, “Una práctica insólita de poder”, en Memorias del Primer Congreso Internacional de Mayistas, UNAM, México, pp. 372-389.

Soustelle, Jacques, 1971, México, tierra india, Sep Setentas, núm. 10, México.

Tozzer, Alfred M., 1982, Mayas y lacandones, Un estudio comparativo, INI, México, segunda edición.
Video documental: Chankín viejo: El Sabio de la Selva Lacandona, Garrick Wilkie Film. 2005.

Villa Rojas, Alfonso, 1985, Estudios Etnológicos. Los Mayas, Serie Antropológicas, núm. 38, UNAM, México.

—, 1967, "Los lacandones. Recursos económicos y organización social", en América Indígena XXVII, 3er trimestre, México, pp. 461-493.

Villoro, Luís, 1984, Los grandes momentos del indigenismo en México, La Casa Chata, México, segunda edición.

Wolf, Eric, 1984, Europay la gente sin historia, Fondo de Cultura Económica, México. 